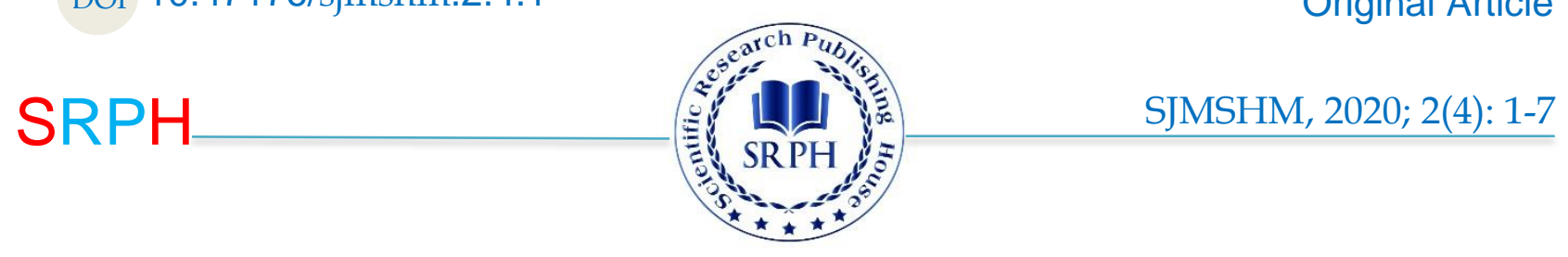

\title{
Effect of the Meteorological Parameters on the Indoor PM2.5 and PM10 Concentrations in a Hospital
}

\author{
Sepideh Keyvani ${ }^{*}$, Mahmoud Mohammadyan ${ }^{2}$ and Elahe Chimehi ${ }^{3}$
}

${ }^{1}$ Department of Occupational Health Engineering, Tehran University of Medical Sciences, Tehran, Iran.

${ }^{2}$ Department of Occupational Health, Faculty of Health, Mazandaran University of Medical Sciences, Sari, Iran.

${ }^{3}$ Social Determinants Research Center of Health and Environmental Health, Faculty of Health, Kashan University of Medical Sciences, Kashan, Iran.

\section{*Corresponding Author: \\ \eyvani.s@gmail.com}

Received: 15 September, 2020

Accepted: 30 October, 2020

Published: 15 November, 2020

\begin{abstract}
Exposure to the particulate matter is related to a variety of acute and chronic health effects. Also, it is an important factor in the indoor air quality in hospitals. The present study aimed to determine the effect of meteorological parameters on the indoor $\mathrm{PM}_{2.5}$ and $\mathrm{PM}_{10}$ concentrations in the operation room, pediatric, and intensive care unit wards in the hospital in Kashan, Iran. The $\mathrm{PM}_{2.5}$ and $\mathrm{PM}_{10}$ concentrations were measured at two indoor sites and one outdoor site in each one of the wards from March to May 2015. Also, the wind rose was drawn for determining the Prevailing wind. The mean indoor and outdoor $\mathrm{PM}_{2.5}$ and $\mathrm{PM}_{10}$ concentrations increased during the study period. The results obtained of wind rose showed that the prevailing wind $(4.5 \%$ of the entire winds) was the direction of the west-southwest. Also, the highest mean outdoor $\mathrm{PM}_{2.5}$ and $\mathrm{PM}_{10}$ concentrations were related to the ambient wind directions of the east-northeast, the west, and the north-northwest in the operation room, pediatric and intensive care unit wards, respectively. According to the findings, there was a positive association between the indoor and outdoor $\mathrm{PM}_{2.5}$ and $\mathrm{PM}_{10}$ concentrations in the wards. Also, the meteorological parameters played an important role in the indoor particle mass concentrations in the study wards in the hospital. The effective meteorological parameters on the particle concentrations were the ambient temperature, wind speed, relative humidity, and rainfall in the hospital. It is asking for improving the indoor air quality of managers and officials to protect the patients and staff against transferred diseases by the particles in the wards in the hospital.
\end{abstract}

Keywords: Hospital, Indoor air, Iran, Meteorology, $\mathrm{PM}_{10}, \mathrm{PM}_{2.5}$

\section{Introduction}

Exposure to particulate matter is related to a variety of acute and chronic health effects such as cardiovascular and respiratory diseases. World Health Organization (WHO) considers particulate matter (PM) as the greatest threat of air pollution [1]. The toxicity of PM depends on its size so that it causes particle deposition in the respiratory system. The PM size contributes to the penetration of particles in buildings [2] and [3]. Sources of PM are man-made and natural. Also, in the other classification, sources of PM are divided into internal and external sources. Internal and external sources and meteorological conditions can affect the
$\mathrm{PM}_{2.5}$ concentration [4]. Meteorological parameters are important agents regarding the re-suspension and subsidence of particles in the atmosphere. Suspended particle concentrations are affected by environmental factors and meteorological conditions. Meteorological conditions can cause a decline of $16 \%$ of $\mathrm{PM}_{2.5}$ concentration [5]. A study revealed that temperature, humidity, wind speed, and wind direction can play a role in the air pollutant concentration [6]. Indoor air quality in hospitals and health buildings requires special attention for the potentially high sensitivity of occupants to PM exposure [7] to [9].

Based on literature reviews, the indoor $\mathrm{PM}_{2.5}$ and $\mathrm{PM}_{10}$ levels are important in the incidence of diseases transferred by the particles, including cardiovascular 
and pulmonary diseases and infections, and the indoor air quality in the health of people in the hospital.

\section{Study's purpose}

The present study was conducted to determine the effect of the parameters on the indoor PM concentration to protect staff and patients against diseases in the Shahid Beheshti Hospital, Kashan, Iran in 2015.

\section{Materials and methods}

\section{Sampling location}

The cross-sectional study was conducted at a hospital in Kashan, Iran. Kashan $\left(33^{\circ} 99^{\prime} \mathrm{N}, 51^{\circ} 41^{\prime} \mathrm{E}\right)$ (Figure 1), located in the north of Isfahan province, the central part of Iran at $924 \mathrm{~m}$ above the sea level. This city has several industrial towns and also it faces the mountains from one side and looks toward the Caver Dash from the other side.

\section{Selected hospital}

Shahid Beheshti Hospital is a general and educative hospital in Kashan that many individuals refer to there from Kashan and some of the neighboring cities for treating and diagnosis check-ups. The hospital is in the vicinity of Kashan University of Medical Sciences and $10 \mathrm{~km}$ away from the Kashan center (Figure 1). The study wards included the operation room and intensive care unit (ICU) wards which were situated in the corners of the northeast and northwest of the first floor, respectively; and the pediatric ward which was located in the corner of the southwest of the third floor.

\section{PM sampling}

The PM sampling was conducted using a Grimm Aerosol Spectrometer model No. 1.108 for over 31 days (from March 8 to May 9, 2015) in the study wards in the Shahid Beheshti Hospital. Because of the limitation in the instrument of measuring PM and also the time, the PM concentration measurement was carried out inside and outside the wards by using a single PM instrument. Also, for decreasing the effects of any diurnal variation across sites, 1-min mean PM mass concentrations were collected over a 5-min period at each sampling location, alternating between indoor and outdoor sites. The PM was evaluated at each sampling location twice a day, once in the morning (08:00 to 12:00), and the afternoon (14:00 to 17:00) at the hospital. In indoor of each one of the wards (room and corridor), the measurements of the PM concentration were conducted at a distance of one meter away from the wall or door and window at a distance of 1.5 meters above the ground level in the breathing zone of an adult. The outdoor PM concentrations were collected at a distance of one meter away from the walls or other obstacles at a height of one meter from the ground level.

The used instrument pumps the air with the flow of a rate of $1.2 \mathrm{~L} / \mathrm{min}$ on a Polytetrafluoroethylene (PTFE) filter. The total weight of PM collected on the filter was measured by a microbalance (Fa-2104 Analytical Electronic Balance) in humidity and temperaturecontrolled room located at the Mazandaran University of Medical Sciences. According to the manufacturer's protocol, the calibration coefficient of the instrument was calculated by dividing the particle concentration by the particle concentration displayed by the sampler over an 8-hour sampling period. Finally, the calibration coefficient was multiplied in all measurements of direct particle readings and the corrected concentration was determined.

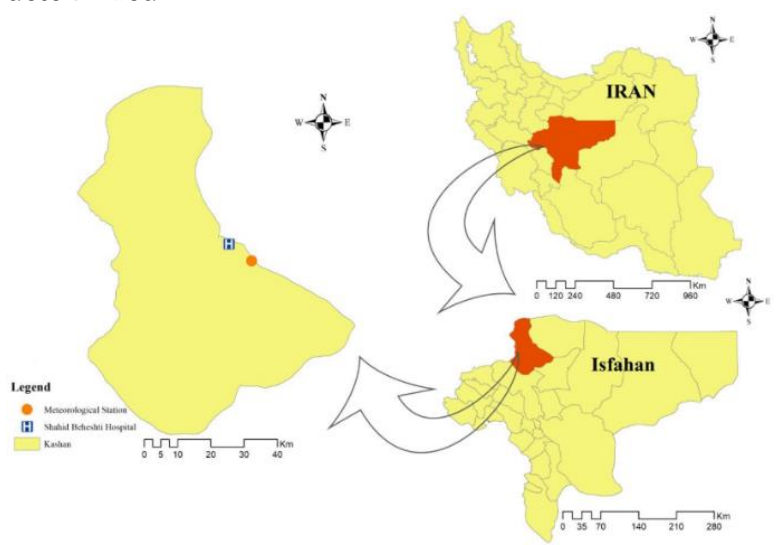

Figure 1. Geographic location of the Shahid Beheshti Hospital in Kashan, Iran.

\section{Meteorological parameters}

The meteorological parameters in the ambient air during the measuring period, including wind speed and direction, mean temperature, relative humidity, rainfall, and weather types including sunny, cloudy, semicloudy, lightly raining, rainy, and thunderstorms were obtained from the Kashan's meteorological station during the measurement periods. Also, to have an overview of wind conditions (wind direction and speed) in Kashan and find its effect on the indoor PM mass concentrations in each one of the wards at the hospital, the wind rose was drawn by entering the related data in WRPLOT View- Freeware.

\section{Statistical analyses}

The Kolmogorov-Smirnov test was used before the analyses for checking the normality of PM mass concentration measurements. The differences between paired PM indoor and outdoor mass concentrations were determined using the non-parametric KruskalWallis test. The available data on the meteorological parameters were analyzed by the Generalized Linear Model (GLM) to confirm whether one or more parameters had a significant impact on dependent 
variables (the indoor $\mathrm{PM}_{2.5}$ and $\mathrm{PM}_{10}$ concentration in each one of the wards). Also, a probability value ( $p$ value) of less than 0.05 was significantly considered at a 95 percent confidence level.

\section{Results}

The mean outdoor $\mathrm{PM}_{2.5}$ concentrations in the operation room, pediatric and ICU wards (91.0, 98.93 and $66.43 \mu \mathrm{g} / \mathrm{m}^{3}$, respectively) were higher than the mean indoor $\mathrm{PM}_{2.5}$ concentrations in the operation room, pediatric and ICU wards (55.25, 57.6 and 54.32 $\mu \mathrm{g} / \mathrm{m}^{3}$, respectively). Also, the mean outdoor $\mathrm{PM}_{10}$ concentrations in the operation room, pediatric and ICU wards (460.93, 531.29 and $312.32 \mu \mathrm{g} / \mathrm{m}^{3}$, respectively) were higher than the mean indoor $\mathrm{PM}_{10}$ concentrations in the operation room, pediatric and ICU wards (212.36, 203.64 and $210.96 \mu \mathrm{g} / \mathrm{m}^{3}$, respectively). There was a significantly positive association between the indoor and outdoor $\mathrm{PM}_{2.5}$ and $\mathrm{PM}_{10}$ concentrations $(\mathrm{P}<0.05)$. Since the sampling of $\mathrm{PM}$ mass concentrations $\left(\mathrm{PM}_{2.5}\right.$ and $\left.\mathrm{PM}_{10}\right)$ in each one of the wards were conducted sequentially during different days, the values of the temperature, relative humidity, and rainfall were different outsides in the hospital wards so that in times of measuring the particles, the averages of parameters including the temperature, rainfall and, relative humidity were 18.62 ${ }^{\circ} \mathrm{C}, 0.086 \mathrm{~mm}$ and $33.31 \%$ in the operation room ward, $32.03^{\circ} \mathrm{C}, 0.071 \mathrm{~mm}$ and $32.96 \%$ in the pediatric ward, and $33.55^{\circ} \mathrm{C}, 0.083 \mathrm{~mm}$ and $32.92 \%$ in the ICU ward, respectively. Given that the results of the wind rose shown in Figure 2, there were calm winds with $63.06 \%$, and $36.94 \%$ direction and speed. Prevailing wind (4.5\% of the entire winds) was the direction of the westsouthwest (WSW).

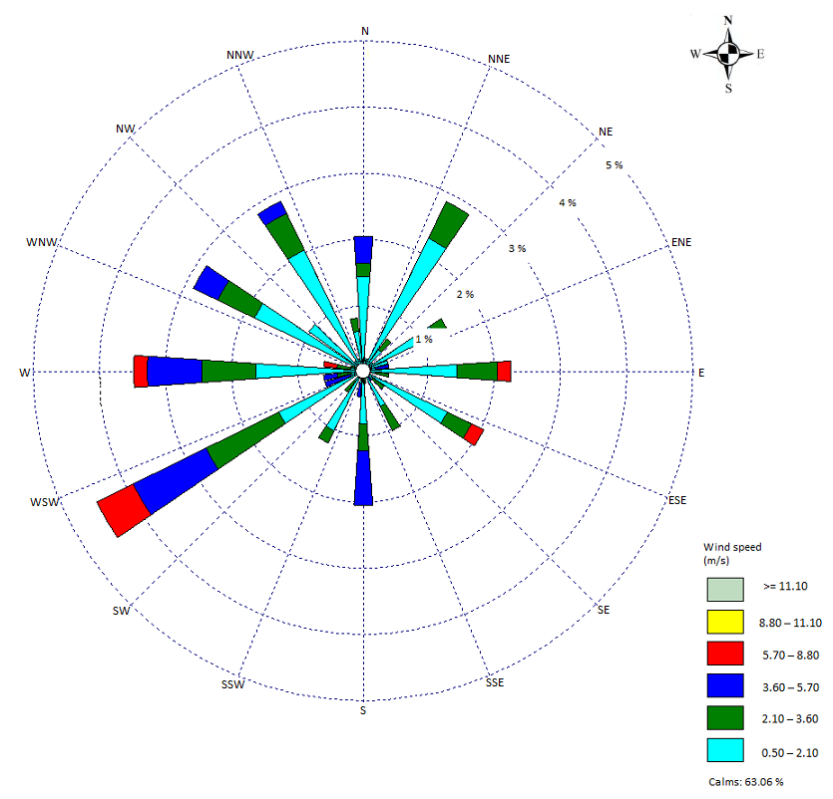

Figure 2. Wind rose of Kashan's meteorological station from March to May 2015.

The results of the Kruskal-Wallis test showed that the mean indoor PM concentrations had significant differences in the study wards $(\mathrm{P}<0.05)$ but the mean $\mathrm{PM}$ concentrations outdoors had significant differences only in the operation room ward $(\mathrm{P}<0.05)$. However, the PM mass concentrations did not differ significantly in the pediatric and ICU wards $(\mathrm{P}>0.05)$. The mean indoor and outdoor $\mathrm{PM}_{2.5}$ and $\mathrm{PM}_{10}$ concentrations increased in the operation room and pediatric wards, respectively during March, April, and May 2015. Human activities and the effect of ventilation and heating systems on the indoor PM concentrations were considered in the previous study.

The wind is an important factor in changing the particle concentrations. The effect of ambient wind speed on the mean outdoor $\mathrm{PM}_{2.5}$ and $\mathrm{PM}_{10}$ concentrations has been shown in Figure 3. The outdoor $\mathrm{PM}_{2.5}$ and $\mathrm{PM}_{10}$ concentrations have an approximately similar trend with increasing the wind speed in each one of the wards in the hospital during March, April, and May 2015. Also, the highest values of outdoor PM concentrations were observed in the speed wind 10,4 , and $4 \mathrm{~m} / \mathrm{s}$ in the operation room, pediatric, and ICU wards, respectively. As it is observed in Figure $3 \mathrm{~b}$, the highest values for the mean outdoor $\mathrm{PM}_{2.5}$ and $\mathrm{PM}_{10}$ concentrations were higher in the pediatric ward than the other two wards.

To determine the effect of ambient wind direction on the outdoor PM concentration levels in the study wards at Shahid Beheshti Hospital, the average weighted particles (AWP) values were first calculated by wind speed by Equation 1 [4]: 
$\mathrm{AWP}=\frac{\sum_{n=1}^{N} P i / W S}{N i}$

In the Equation, $\mathrm{Pi}$ is the outdoor $\mathrm{PM}_{2.5}$ or $\mathrm{PM}_{10}$ concentration, WS is the ambient wind speed and $\mathrm{Ni}$ is the number of directions. Figure 4 shows the mean outdoor PM concentration levels in the ambient wind direction in the wards from May to March 2015. The highest mean outdoor $\mathrm{PM}_{2.5}$ and $\mathrm{PM}_{10}$ concentrations were related to the wind directions of the eastnortheast (ENE), the west (W) and the northnorthwest $(\mathrm{NNW})$ in the operation room, pediatric and ICU wards, respectively.

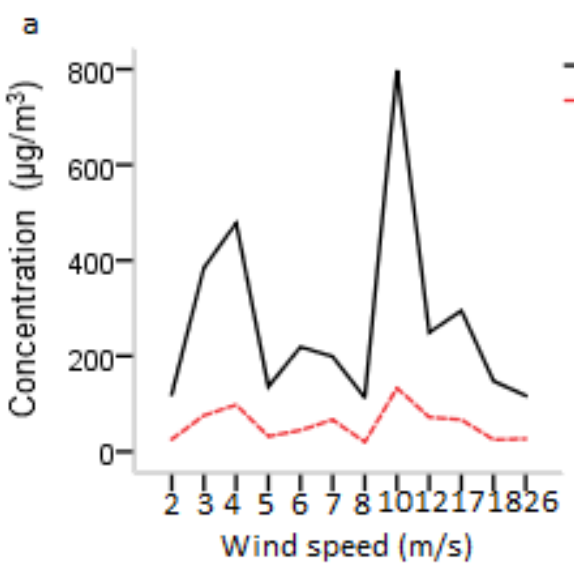

b
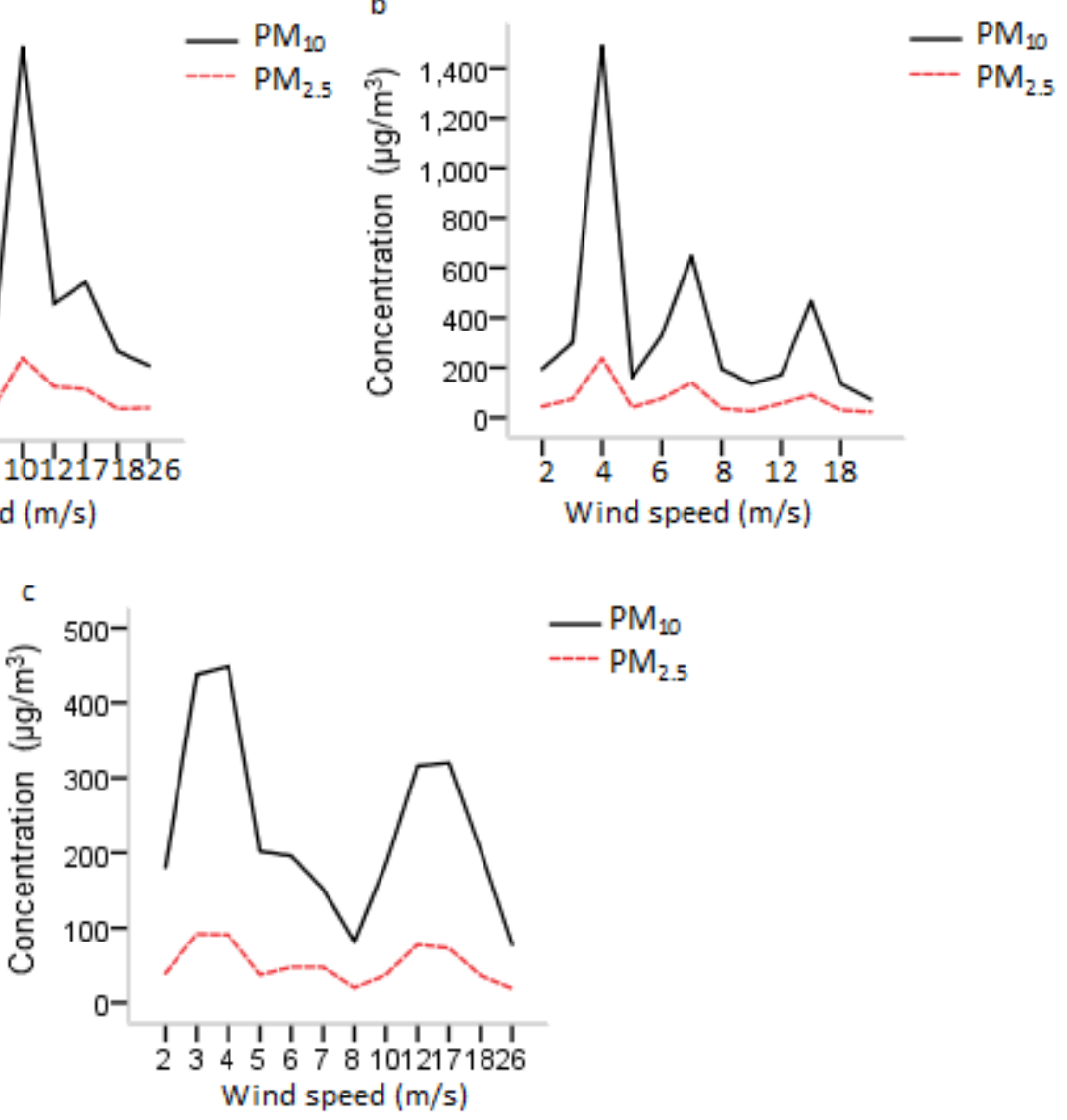

Figure 3. The mean outdoor $\mathrm{PM}_{2.5}$ and $\mathrm{PM}_{10}$ concentrations in the outdoor wind speed in the operation room (a), pediatric (b) and ICU (c) wards in Shahid Beheshti Hospital during March to May 2015.

The results revealed that the mean outdoor $\mathrm{PM}_{2.5}$ and $\mathrm{PM}_{10}$ concentrations were higher than the mean indoor PMs $\left(\mathrm{PM}_{2.5}\right.$ and $\left.\mathrm{PM}_{10}\right)$ concentration levels. The highest mean indoor and outdoor $\mathrm{PM}_{10}$ concentration level belonged to the pediatric ward $\left(57.61 \mu \mathrm{g} / \mathrm{m}^{3}\right.$ and $98.93 \mu \mathrm{g} / \mathrm{m}^{3}$, respectively). The mean indoor and outdoor $\mathrm{PM}_{2.5}$ and $\mathrm{PM}_{10}$ concentrations in the wards were higher than the 24-hours WHO and USEnvironmental Protection Agency (US-EPA) standards [10] and [11].

According to the obtained results of the GLM test, there was no significant association between the indoor $\mathrm{PM}_{2.5}$ and $\mathrm{PM}_{10}$ concentrations and the weather types in each one of the wards at Shahid Beheshti Hospital with the meteorological parameters $(\mathrm{P}>0.05)$. In other words, weather types did not affect indoor PM concentrations.

The results of a significant association between the meteorological parameters and the indoor $\mathrm{PM}_{2.5}$ and $\mathrm{PM}_{10}$ concentrations in the pediatric and ICU wards at Shahid Beheshti Hospital have been indicated in Table 1. In the pediatric ward, the indoor $\mathrm{PM}_{10}$ concentration had a positive association with the ambient wind speed and an inverse association with the ambient relative humidity. Also, an inverse association was observed between the indoor $\mathrm{PM}_{2.5}$ concentration and the ambient temperature and rainfall in the ward. 
a

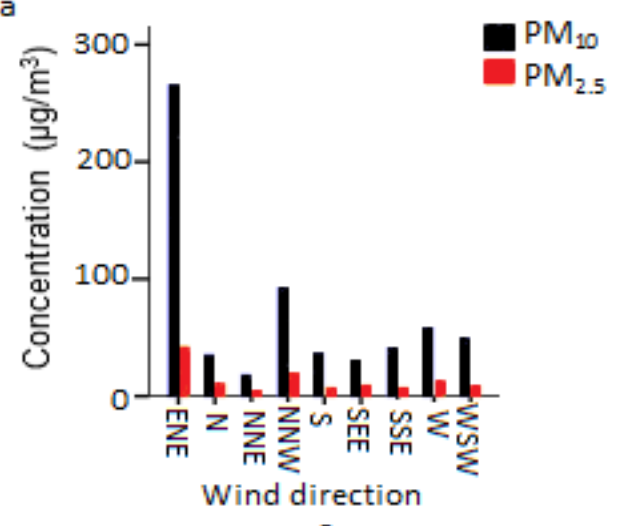

b

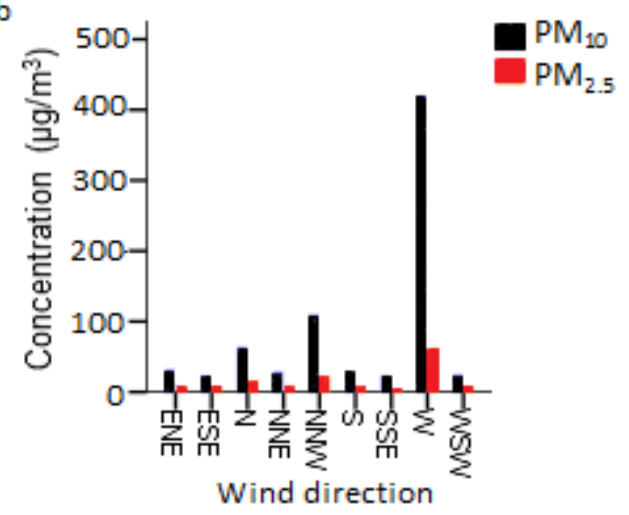

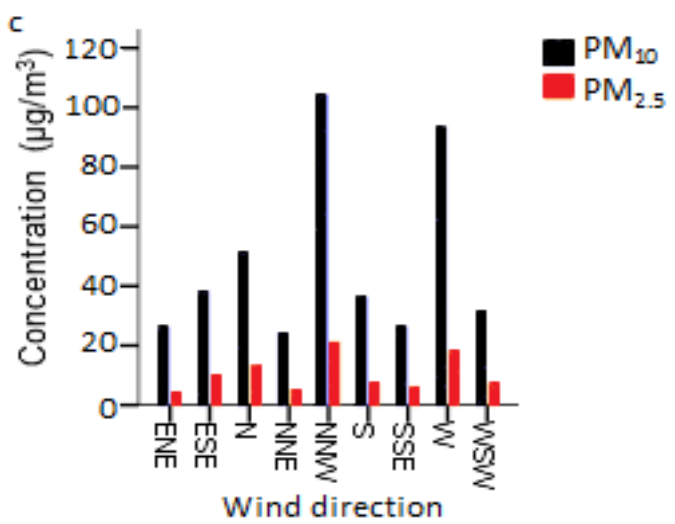

Figure 4. AWP values of ambient wind direction for the outdoor $\mathrm{PM}_{2.5}$ and $\mathrm{PM}_{10}$ concentrations in the operation room (a), pediatric (b), ICU (c) in Shahid Beheshti Hospital in 2015.

In the ICU ward, it was observed an inverse association between the indoor $\mathrm{PM}_{2.5}$ concentration and the ambient relative humidity (Table 1 ). In the present study, the prevailing wind was blowing from the WSW direction toward Kashan from March to May 2015. In the WSW direction, wind passes through the desert regions of Iran and also neighboring countries to Kashan. So, it can lead to an increase in the concentration of particles in the air of Kashan and as a result, the outside air of the hospital.

Wind causes a shift in the PM concentration in different speed values and directions so that the wind direction is an effective parameter in the AWP. In the current study, the highest values of AWP for the outdoor $\mathrm{PM}_{2.5}$ and $\mathrm{PM}_{10}$ concentrations were approximately seen in the orientation of the wards. So that, the orientation of the operation room ward was in the NE and there were the highest values of outdoor AWP for the outdoor PM concentrations in the ENE. Also, the orientations of the pediatric and ICU had been located in the SW and NW, respectively and the highest values AWP for the outdoor PM concentration were in the $\mathrm{W}$ and NNW, respectively.

Table 1

Significant results $(\mathrm{P}<0.05)$ on the association between the meteorological parameters and the indoor $\mathrm{PM}_{2.5}$ and $\mathrm{PM}_{10}$ concentrations in the pediatric and ICU wards at Shahid Beheshti Hospital from March to May 2015.

\begin{tabular}{|c|c|c|c|c|c|c|c|}
\hline \multirow[b]{2}{*}{ Ward } & \multicolumn{2}{|c|}{ Variables/Parameters } & \multirow[b]{2}{*}{ B } & \multirow[b]{2}{*}{$\mathrm{Se}$} & \multicolumn{3}{|c|}{ Hypothesis Test } \\
\hline & Dependent & Independent & & & Wald Chi-Square & df & p-value \\
\hline \multirow{6}{*}{ Pediatric } & $\mathrm{PM}_{2.5}$ & Constant & -2.52 & 38101.19 & 0.00 & 1 & 1.00 \\
\hline & & Rainfall & -1.72 & 0.62 & 7.70 & 1 & 0.006 \\
\hline & & *Temp & -0.081 & 0.027 & 8.66 & 1 & 0.003 \\
\hline & $\mathrm{PM}_{10}$ & Constant & 25.66 & 35444.15 & 0.00 & 1 & 0.99 \\
\hline & & tWS & 0.59 & 0.12 & 24.93 & 1 & 0.00 \\
\hline & & $\neq \mathrm{RH}$ & -0.21 & 0.048 & 19.09 & 1 & 0.00 \\
\hline \multirow[t]{2}{*}{$\mathrm{ICU}$} & $\mathrm{PM}_{2.5}$ & Constant & -34.34 & 43727.00 & 0.00 & 1 & 0.99 \\
\hline & & RH & -.038 & 0.14 & 7.42 & 1 & 0.006 \\
\hline
\end{tabular}

*Temperature; ${ }^{*}$ Wind speed; $¥$ Relative humidity. 
Since the outdoor concentrations of $\mathrm{PM}_{2.5}$ and $\mathrm{PM}_{10}$ are high considering the different meteorological conditions in the Kashan, the value of AWP in the study was higher than the other studies [12] and [4]. In the current study, there was an inverse association between the indoor $\mathrm{PM}_{2.5}$ concentration and rainfall in the pediatric ward (Table 1). In this way, rainfall can cause to subside the particles suspended in the air on the ground and decreased the $\mathrm{PM}_{2.5}$ concentration. On the other hand, there was an inverse association between the ambient relative humidity and the indoor $\mathrm{PM}_{10}$ concentration in the pediatric ward. Also, this result was gained for the indoor $\mathrm{PM}_{2.5}$ concentration in the ICU ward (Table 1). In contrast, some studies did not find a significant association between the ambient relative humidity and the particle concentrations [13]. In the present study, the effective meteorological parameters on the indoor PM mass concentrations were the ambient temperature, rainfall, wind speed, and relative humidity in the pediatric ward in the hospital. Also, the only effective meteorological parameter on the PM concentration was the ambient relative humidity in the ICU ward in the hospital. In the operation room ward, the meteorological parameters were not effective in the indoor PM concentrations.

\section{Conclusion}

In the present study, the effect of the meteorological parameters on the indoor $\mathrm{PM}_{2.5}$ and $\mathrm{PM}_{10}$ mass concentrations were investigated in the operation room, pediatric, and ICU wards at the Shahid Beheshti Hospital in Kashan, Iran from May to March 2015. There was a positive association between the indoor and outdoor $\mathrm{PM}_{2.5}$ and $\mathrm{PM}_{10}$ concentrations in the wards. The mean indoor and outdoor $\mathrm{PM}_{2.5}$ and $\mathrm{PM}_{10}$ concentrations increased in the operation room and pediatric wards, respectively during the study period. The mean indoor and outdoor $\mathrm{PM}_{2.5}$ and $\mathrm{PM}_{10}$ concentrations in the wards were higher than the 24hours WHO and US-EPA standards. The mean outdoor $\mathrm{PM}_{2.5}$ and $\mathrm{PM}_{10}$ concentrations were higher than the mean indoor $\mathrm{PM}_{2.5}$ and $\mathrm{PM}_{10}$ concentration levels. The highest mean indoor and outdoor $\mathrm{PM}_{2.5}$ concentration levels belonged to the pediatric ward. Also, there were the highest mean indoor and outdoor $\mathrm{PM}_{10}$ concentration levels in the operation room and pediatric wards, respectively. Prevailing wind $(4.5 \%$ of the entire winds) was the direction of the WSW. The highest mean outdoor $\mathrm{PM}_{2.5}$ and $\mathrm{PM}_{10}$ concentrations were related to the wind directions of the ENE, W and NNW in the operation room, pediatric and ICU wards, respectively. So that the highest values of AWP for the outdoor $\mathrm{PM}_{2.5}$ and $\mathrm{PM}_{10}$ concentrations were approximately seen in the orientation of the study wards. There was no significant association between the indoor $\mathrm{PM}_{2.5}$ and $\mathrm{PM}_{10}$ concentrations and the weather types including sunny, cloudy, semi-cloudy, lightly raining, rainy, and thunderstorms in each one of the wards in the hospital. Also, the effective meteorological parameters on the indoor PM concentrations were the ambient air temperature, wind speed, relative humidity, and rainfall and ambient in the wards in the hospital. In other words, the parameters contributed to the indoor PM levels in the Shahid Beheshti hospital. Finally, the study can suggest being conducted more studies on the effect of meteorological parameters on the indoor PM in health facilities and hospitals.

\section{Acknowledgments}

Some of the results of the research obtained from the project approved by the Mazandaran University of Medical Sciences. The authors thank the manager and personnel of the Shahid Beheshti Hospital for their contribution. They also thank the sincere assistance of Mr. Abbas Aghavani (head of Kashan's meteorological administration) and Nasrin Rostami (Department of Environmental Health Engineering, Tehran University of Medical Sciences).

\section{References}

1. Mills NL. et al. Adverse cardiovascular effects of air pollution. Nat Clin Pract Cardiovasc Med. 2009; 6(1): 3644.

2. Liu DL, Nazaroff WW. Particle penetration through building cracks. Aerosol Sci Technol. 2003; 37(7): 565573.

3. Rim D, Wallace L, Persily A. Infiltration of outdoor ultrafine particles into a test house. Environ Sci Technol. 2010; 44(15): 5908-5913.

4. Wang J, Ogawa S. Effects of meteorological conditions on PM2.5 concentrations in Nagasaki, Japan. Int J Environ Res Publ Health, 2015; 12(8): 90899101.

5. Yang L, Wu Y, Davis JM, Hao J. Estimating the effects of meteorology on $\mathrm{PM}_{2.5}$ reduction during the 2008 summer olympic games in Beijing, China. Front Environ Sci Eng China, 2011; 5(3): 331-341.

6. Elminir HK. Dependence of urban air pollutants on meteorology. Sci Total Environ. 2005; 350(1-3): 225-237. 7. Chamseddine A, Fadel M. Exposure to air pollutants in hospitals: indoor-outdoor correlations. WIT Trans Built Environ. 2015; 168: 707-716.

8. Eames I, Tang J, LI Y, Wilson P. Airborne transmission of disease in hospitals. J Royal Soc Interface, 2009; 6: S697-S702.

9. Slezakova K, Alvim-Ferraz M, Pereira M. Elemental characterization of indoor breathable particles at a Portuguese urban hospital. I Toxicol Environ Health, 2012; 75: 13-15, 909-919. 
10. Esworthy R. 2006 National Ambient Air Quality Standards (NAAQS) for fine particulate matter (PM2.5): designating nonattainment areas, congressional research service report. 2015; December 23: Fayetteville, USA.

11. WHO. Air quality guidelines: global update 2005, particulate matter, ozone, nitrogen dioxide and sulfur dioxide. WHO Regional Office for Europe, Copenhagen. 2006.
12. Li X, Feng YJ, Liang HY. The impact of meteorological factors on PM2.5 variations in Hong Kong. IOP Conf Series: Earth Environ Sci. 2017; 78(1): 012003.

13. Massey D, Kulshrestha A, Masih J, Taneja A. Seasonal trends of PM10, PM5.0, PM2.5 \& PM1.0 in indoor and outdoor environments of residential homes located in North-Central India. Build Environ. 2012; 47: 223-231.

\section{SJMSHM}

Copyright: (C) 2020 The Author(s); This is an open-access article distributed under the terms of the Creative Commons Attribution License (http://creativecommons.org/licenses/by/4.0), which permits unrestricted use, distribution, and reproduction in any medium, provided the original work is properly cited.

Citation: Keyvani S, Mohammadyan M, Chimehi E. Effect of the Meteorological Parameters on the Indoor PM2.5 and PM10 Concentrations in a Hospital. SJMSHM. 2020; 2(4): 1-7.

https://doi.org/10.47176/sjmshm.2.4.1 